\title{
O LEITOR E O COTIDIANO NA HISTÓRIA DO JORNATISMO
} AUDIENCE AND EVERYDAY LIFE ON JOURNALISM HISTORY

\author{
LETICIA CANTARELA MATHEUS ${ }^{1}$
}

\begin{abstract}
Resumo: O artigo apresenta uma reflexão sobre a participação do público nos processos jornalísticos a partir de uma comparação histórica. Traz exemplos empíricos de diferentes modos de interação do leitor com os principais periódicos impressos que circularam no Rio de Janeiro nas últimas três décadas do século XIX. Elabora a hipótese de que as condições para essa participação tenham sido dois fatores: a nova possibilidade tecnológica, fornecida pela ampliação da telegrafia, e a introdução dos temas do cotidiano como objetos noticiosos. O corpus da pesquisa é formado por dez periódicos que circularam entre 1870 e 1900: Jornal do Commercio, O Fluminense, Jornal do Brasil, Gazeta de Notícias, Diário do Rio de Janeiro; Gazeta da Tarde; O Paiz; A Pátria, Diário de Notícias, A Cidade do Rio.
\end{abstract}

Palavras-chave: jornalismo; público; participação; cotidiano; história do jornalismo.

Abstract: This paper analyzes the audience participation in journalistic processes by means of a historical comparison. Through empirical examples, it shows different interaction modes between readers and the main printed periodicals which have circulated in Rio de Janeiro during the last three decades of the 19th century. It elaborates the hypothesis that two factors supported the conditions for such participation: a new technological possibility provided by the expansion of the telegraph, and the introduction of the themes of everyday life as objects for such news. The research corpus consists of ten newspapers that circulated between 1870 and 1900: Jornal do Commercio, O Fluminense, Jornal do Brasil, Gazeta de Notícias, Diário do Rio de Janeiro; Gazeta da Tarde; O Paiz; A Pátria, Diários de Notícias, A Cidade do Rio.

Keywords: journalism; audience; participation; everyday life; history of journalism.

Quando ainda em 1977, Muniz Sodré publicou “O monopólio da fala”, a televisão era a mídia emblemática da sociedade de massa e de seus modos de comunicação. A TV sintetizava a condição do cidadão como espectador da vida pública. A “usabilidade” desse meio, seu modo de consumo, era representada pela hipnose, pelo silêncio do indivíduo diante

\footnotetext{
${ }^{1}$ Doutora em Comunicação Social pela UFF (2010). Professora da Universidade do Estado do Rio de Janeiro (Uerj). Professora da Faculdade de Comunicação Social da Universidade do Estado do Rio de Janeiro (Uerj). Autora dos livros "Comunicação, tempo, história: tecendo o cotidiano em fios jornalísticos" e "Narrativas do Medo: o jornalismo de sensações além do sensacionalismo". Pesquisa o jornalismo no final do século XIX, com apoio da FAPERJ. leticia_matheus@yahoo.com.br
} 
da tela. Tal condição traduzia mais do que uma simples postura física de acordo com a materialidade daquele meio. Servia como metáfora do comportamento social.

Quando surgiu a internet, o público encontrou a oportunidade de entrar em contato com inúmeros indivíduos direta e simultaneamente e ganhou maior visibilidade nas mídias digitais. Porém não é possível afirmar que o público não participasse de alguma forma do processo jornalístico em tempos mais remotos.

Sodré (1977) argumentava que para construir cultura é preciso que haja a livre circulação das significações linguísticas, o que só é garantido pela reciprocidade das trocas linguísticas/simbólicas. A troca é fundamental porque é ela que organiza a cultura, que não pode se fundar sob um simples monopólio da fala. É preciso permitir que o jogo simbólico se mantenha aberto para múltiplas vozes e experiências, de modo que as contradições possam emergir. Assim, a TV foi entendida como forma de controle social do diálogo, o que impossibilitava a troca porque era ela quem falava sozinha.

O resgate desse debate a título de introdução serve para discutir a atual cultura participativa. É preciso perguntar se os novos parâmetros de participação se referem à possibilidade de que o jogo esteja aberto, se efetivamente impactam os procedimentos jornalísticos ou se nos encontramos simplesmente diante da ampliação do conjunto de fontes. Com o intuito de esboçar essa discussão, este artigo traz uma perspectiva histórica, de modo a fornecer um ponto de vista alternativo, a partir do olhar para o passado. Ele trata do surgimento de uma nova tecnologia que, na sua época, também impactou o fazer jornalístico: a telegrafia. No momento em que os jornais brasileiros começaram a fazer uso sistemático do telégrafo, no final do século XIX, assumiram uma configuração muito mais noticiosa e ampliaram seu espectro de fontes. Entretanto, a participação do público não estava condicionada apenas ao recurso tecnológico, mas à introdução dos temas (e do tempo) do cotidiano como material jornalístico e de recursos de interação como jogos e promoções.

A pesquisa, que é qualitativa e ainda está em desenvolvimento, investiga, portanto, a presença do leitor e de sua colaboração a partir da interpretação dos textos publicados nos principais diários que circularam entre 1870 e 1900 no Rio de Janeiro: Jornal do Commercio, O Fluminense, Jornal do Brasil, Gazeta de Notícias, Diário do Rio de Janeiro; Gazeta da Tarde; O Paiz; A Pátria, Diário de Notícias, A Cidade do Rio. A seleção das edições estudadas se dá por amostragem de um mês a cada cinco anos, ou em intervalos 


\section{míDiA

menores, de acordo com possíveis falhas nas coleções da Biblioteca Nacional ou de acordo com a necessidade de confirmar a continuidade ou não de alguma prática específica.

\section{O cotidiano nas páginas e os jogos interativos}

Não foi apenas o telégrafo que trouxe a dimensão da colaboração do público com os jornais, já que havia outras práticas simultâneas que nos dão, hoje, a estranha sensação de um longínquo parentesco com a ideia de interatividade. Participação, interatividade e colaboração são conceitos que frequentemente têm sido intercambiados, embora os consideremos não exatamente como sinônimos. De fato, tratam da relação do público com a mídia, mas acreditamos que cada um possua uma adequação própria que precisa ser consolidada, embora não tenhamos a pretensão de resolver esse problema neste trabalho.

A colaboração tende a se referir à inclusão do público na produção noticiosa (ROCHA e BRAMBILLA, 2009), isto é, como fornecedor de conteúdo, mas não é incomum encontrar esse princípio nas referências ao webjornalismo participativo (PRIMO e TRÄSEL, 2006). Já a ideia de participação carrega consigo a dimensão política da colaboração (FONSECA e LINDEMANN, 2007), em consonância com a preocupação de Sodré mencionada no início. O conceito de participação traz uma leitura mais ampla (QUADROS, 2005), podendo se referir tanto à interação simples, como a resposta a jogos e perguntas, quanto num nível mais ativo, de envio espontâneo de notícias.

Dos três, o conceito que parece mais claramente destacado é o de interatividade, como a dimensão da possibilidade técnica de interferência no conteúdo das mídias. Essa interferência se dá desde um plano mais simples, de simples “feedback”, até uma ação proativa na escolha de conteúdos (LEMOS, 1998). Seria, então, a partir desse último nível mais intenso, de remessa de conteúdo, que surgiria a prática colaborativa. Nossa hipótese é que o telégrafo tenha intensificado a possibilidade de colaboração com os jornais e entre os jornais.

Algum nível de ação está presente em qualquer processo comunicacional e em quaisquer de suas etapas, incluindo os momentos de recepção, pois a produção de sentido implica o preenchimento das "lacunas" das múltiplas textualidades que nos são apresentadas na vida social. Entretanto, esse nível de ação simbólica não se confunde com os conceitos de participação, colaboração e interatividade, esta última que é uma condição de uso de novas 


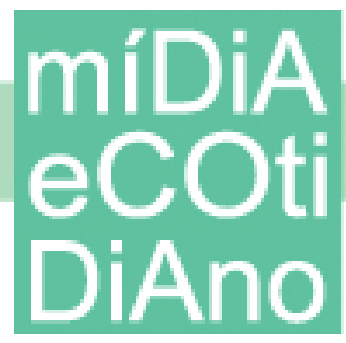

mídias digitais que funcionam como plataforma e novo modo operacional do jornalismo. ${ }^{2}$ Trata-se de uma condição técnica que acarreta um comportamento. Essa condição de uso propiciou ou estimulou várias formas de interação, como a discussão em fóruns, conversas em chats, integração a redes sociais, a comunidades virtuais, ou o simples envio de e-mails para os sites noticiosos, fazendo perguntas e sugestões, deixando comentários nas postagens dos jornais online, até a iniciativa de produzir páginas e blogs pessoais e de buscar informação por conta própria em bancos de dados virtuais. Essas iniciativas podem ou não significar índices de maior participação. Por isso, não se deve associar de modo linear que uma crescente interatividade venha a se tornar uma crescente participação cívica, pois o grau de proatividade e a intenção na atividade podem ser muito diversos.

Como explicou recentemente, ${ }^{3}$ Sodré se preocupava com a capacidade de resposta simbólica à televisão, com a possibilidade de o público participar de modo ativo na formação do mercado simbólico e das regras de formulação de valor nesse mercado, para usar os conceitos de Bourdieu (2008). Isso nos leva a crer que da interatividade técnica da internet não decorre necessariamente um diálogo real, podendo significar um simulacro de diálogo, traduzindo ainda uma cidadania passiva, regida pela lógica do consumo. Isto é, a posição dos cidadãos no mercado simbólico pode permanecer a mesma.

O consumo nunca foi a etapa final do processo de comunicação, mas talvez fosse mais difícil, para as empresas de comunicação e para os pesquisadores, perceber seus efeitos no comportamento social com tantas nuances quanto agora. Esse "feedback" do público podia ser observado de forma restrita, por cartas, telefonemas, mas, hoje, o retorno é imediato nos comentários e na redistribuição daquela informação (compartilhamentos, envios por e-mail, retwittagens). A audiência/leitor é certamente apenas uma das etapas do consumo, que hoje se confunde com a própria participação. Na maior parte das vezes, entretanto, a participação não se reflete numa maior autonomia do público ou em verdadeiro diálogo.

\footnotetext{
${ }^{2}$ A internet, por exemplo, não "funciona” sem que o usuário realize uma ação ou uma sequencia de ações que pressupõem escolhas. Sobre interatividade, $c f$. principalmente Primo (2005) e Lemos (1998).

${ }^{3}$ Em entrevista gentilmente concedida ao programa “Olhar Universitário”, do Centro Universitário Plinio Leite (Niterói), o professor Muniz Sodré avaliou sua obra, 40 anos depois do lançamento, e manifestou preocupação com o fato de a participação ainda se traduzir muito mais em termos de consumo do que de participação política.
} 
O princípio da colaboração pressupõe que ela seja gratuita, baseada na lógica do voluntariado, o que não significa que não possa haver algum interesse comercial indireto. ${ }^{4}$ Lembrando antigas práticas, não devemos ignorar que os jornais do século XIX obtinham as informações a ser noticiadas graças a uma rede de correspondentes, voluntários ou não. Por volta dos anos 1890, essa prática havia se atualizado em função do uso da telegrafia e foi independente dos serviços da agência francesa Havas (MATHEUS, 2012), instalada no Rio de Janeiro em 1874. É tentador chamar esse hábito de envio de telegramas às redações de uma espécie de jornalismo colaborativo. Se usar esse conceito seria anacronismo, pelo menos podemos afirmar que havia sim uma rede de colaboração entre jornais e alguns leitores privilegiados, como explicamos a seguir.

Quando se fala em cultura participativa, o que primeiro se deve ter em mente é tentar responder às seguintes perguntas, que ajudam a complexificar suas implicações nos processos jornalísticos: quem participa no quê e com o quê? E, ainda, como é essa contribuição?

A primeira questão é que o que se chama público ou usuário ou interagente ${ }^{5}$ podem ser coisas muito diferentes. Pode ser o público leigo querendo apenas colaborar espontaneamente (ou incitado pelo jornalista) com uma pauta que ele julga importante. Esse mecanismo, na realidade, sempre funcionou. Nesse caso, o usuário é uma mera fonte, como era no passado, porém se tornou mais frequente ela ser uma fonte espontânea, que passou a ter a chance de observar a produção simultânea do produto jornalístico. Esse usuário pode também ser um jornalista profissional desempregado, freelancer ou independente que encontrou na internet a melhor forma de trabalhar e de ganhar visibilidade.

A segunda questão é com o que essas pessoas colaboram. Em primeiro lugar, elas podem estar colaborando simplesmente na produção de empresas já instituídas, na maior parte das vezes, grupos multimídia que inauguraram suas atividades em ambientes tradicionais, como a imprensa ou a televisão. Essas pessoas estão colaborando de graça, servindo como fonte, como sempre ocorreu na história do jornalismo. Além disso, os usuários de internet podem estar simplesmente divulgando informações sem maiores ambições que elas saiam da sua esfera privada de grupos de amigos no Twitter, no Facebook, ou em outra rede. Eles estão

\footnotetext{
${ }^{4}$ Sobre webjornalismo colaborativo, $c f$. Rocha e Brambilla (2009).

${ }^{5}$ Primo coloca o usuário numa perspectiva ativa, preferindo o conceito de interagente, com o que concordamos.
} 
publicizando a notícia como fazia antes normalmente na sua rede de relações pessoais. Nesse caso, a maior parte das notícias é notícia apenas para ele e para seu grupo mais íntimo, não havendo, portanto, amplo interesse público que justifique a intervenção jornalística. Entretanto, em muitos casos, essa notícia pode vir a se tornar de interesse público e virar notícia jornalística, com o trabalho de um repórter sobre ela, que apenas identificou a potencialidade da pauta a partir da web ou que realizou parte da apuração em ambiente digital. Mais uma vez, está se falando simplesmente da "boa e velha” condição de fonte, com a diferença que o jornalista irá interagir com ela em outro ambiente, outra plataforma, que não o telefone ou a entrevista presencial.

O que pode ocorrer de realmente novo é a flexibilização dos critérios de noticiabilidade por pressão do público. As empresas podem não estar afinadas com o interesse do público e uma notícia de um leigo na rede despertar tanto interesse que e a mídia constituída será obrigada a reformular ou flexibilizar seus critérios de noticiabilidade. Mas esse movimento continua sendo uma questão comercial, podendo estar ou não próxima a uma lógica da participação política efetiva. Trata-se de um recurso empreendedor da empresa, mas que, de certa forma, expõe o poder do público de participar da decisão sobre o que é notícia. Em terceiro lugar, esse usuário, que posteriormente chamarei de público, pode colaborar em sistemas alternativos de informação, podendo ou não ter a mediação de um jornalista profissional.

Por fim, a terceira questão que se coloca é como efetivamente o público colabora. Pode ser com simples comentários que não ultrapassam o plano da interação quase automática e recreativa. Esses comentários não deixam de ser importantes, pois ampliam o sentido da notícia num jogo intertextual, além, é claro, de servir como índice de popularidade da notícia. Assim, as empresas contam com pesquisas de opinião instantâneas e gratuitas, podendo ajustar instantânea e permanentemente sua produção, seu enquadramento etc. Mapeando essas práticas, é possível dizer que a segunda forma de colaboração é quando o público se transforma em divulgador espontâneo das notícias dos sites das empresas jornalísticas.

Uma terceira forma é o envio de sugestões de pauta, e material como fotografias e vídeos de flagrantes do cotidiano que podem ou não se tornarem pautas, também como já ocorria antes da internet. Esse tipo de material costuma se restringir à cobertura local, uma vez que está enraizado na experiência do cotidiano da cidade, como a problemas de 


\section{míDiA

conservação, de trânsito, de crimes etc. e são usadas pelas empresas em substituição ao trabalho de um jornalista, como mera ilustração, ou fotolegenda, sem que se desenvolva uma investigação sobre aquilo. Um leitor não compra uma passagem para Damasco, para poder postar suas impressões sobre a guerra na Síria, nem vai à Brasília visitar o Congresso Nacional para alimentar seu perfil no Facebook ou no Twitter, mas, quando se depara com um vazamento de esgoto gigantesco na porta de casa ou no caminho para o trabalho, pode fotografar a cena e enviar o material para uma redação de um jornal. O problema está em o jornalismo abrir mão do caráter investigativo intrínseco à profissão e se converter em um simples banco de publicações aleatórias, o que tem se tornado o fluxo noticioso online. Era exatamente assim que operavam os jornais no final do século XIX, como coletâneas. Embora hoje ainda exista o agravante da ampla disponibilização de espaço virtual, como se tudo “coubesse” como notícia. E, finalmente, em quarto lugar, está a veiculação de relatos e informações de uma pessoa que não é jornalista num órgão jornalístico, mas que podem ser capturados por um profissional para se tornar pauta ou complemento de apuração.

Portanto, há inúmeras formas de participação-colaboração. Algumas inéditas, outras nem tanto. Bastam lembrar as charadas, enigmas, palavras-cruzadas, desde o século XIX, além das promoções, o envio de reclamações, que posteriormente passaram a ser absorvido como sugestão de pauta e investigadas, o envio de fotografias, e, não podemos esquecer, a participação por telefonemas e cartas, que sempre abasteceram as redações diariamente com as mais variadas contribuições do público - desde fonte, sugestão de pauta como denúncias -, até reclamações sobre a condução das próprias coberturas jornalísticas. Portanto, as tecnologias digitais, a começar com os e-mails e posteriormente blogs e redes sociais, facilitaram ou intensificaram esse processo interativo, no sentido de o público procurar interferir no conteúdo do jornal ou querer simplesmente se divertir pela própria interação, como no caso dos enigmas e charadas tão populares nas últimas décadas do século XIX, equacionado uma experiência lúdica com o consumo de jornal.

\section{Popularização dos jornais e participação do leitor}

No final do século XIX, os jornais se empenharam em mobilizar a interação do leitor. Antes da ideia de credibilidade, o sucesso comercial e simbólico dos periódicos foi obtido graças à mobilização que conseguiram no público. Para isso, foram utilizadas algumas 
estratégias de aproximação, no intuito de construir esse mesmo público potencial, aumentando suas tiragens num momento que a imprensa assumia moldes industriais. Com uma população de pouco mais de 600 mil habitantes no Rio de Janeiro na virada do século, a soma das tiragens dos principais diários alcançava 135 mil exemplares. Isso se a tiragem declarada fosse confiável. Entretanto, mesmo que esse número estivesse superdimensionado, é inegável que o público leitor de periódicos tinha crescido consideravelmente desde meados daquele século. E a maior intensificação se deu exponencialmente nas últimas décadas (BARBOSA, 2010).

Entre as diferentes estratégias de aproximação estavam promoções, oferta de brindes, publicação dos folhetins, notícias de crimes e, principalmente, as colunas dedicadas às reclamações, tais como "Queixas do Povo” (Jornal do Brasil), “A Pedidos” (Jornal do Commercio), "Reclamações do Povo (Gazeta de Notícias), “Queixas e Reclamações” (O Paiz), conforme relata Barbosa (ibid.).

Mas esses não eram os únicos espaços ou as únicas formas de o leitor participar da rotina dos jornais. Foi possível ao leitor, naquele momento, ver-se com mais frequência tanto como personagem das narrativas jornalísticas quanto como fonte. Além disso, surgiram outras formas de interatividade, como os enigmas e as charadas, publicadas num dia e respondidas na edição seguinte, com a distribuição de prêmios para os leitores que as solucionassem. As piadas e os poemas enviados pelos leitores, por solicitação dos jornais, também eram publicados diariamente, como forma de colaboração sistemática dos assinantes. Havia ainda o estímulo à visitação aos escritórios.

Sem o intuito de um mapeamento completo das múltiplas formas de interação do público, procuramos situações particulares que pudessem ilustrar a dinâmica leitor-jornal, tentando compreender sua mútua interferência. A primeira hipótese quanto aos parâmetros sobre os quais essa participação se dava tem o leitor como personagem. Embora ainda não fosse o momento da adoção da entrevista como técnica de reportagem, as histórias humanas já começavam a aparecer, conforme pudemos perceber em dezenas de exemplares.

Por exemplo, o jornal A Pátria, que circulava no município de Niterói (RJ), possuía conteúdo fundamentalmente local. Com assinatura anual de oito mil réis, A Pátria falava do povo não de forma genérica, como retórica política, mas de modo específico, como personagens do noticiário. Em outubro de 1871, por exemplo, o jornal contou a história de um 


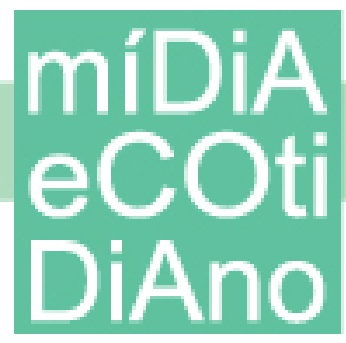

morador do bairro da Ponta D’Areia que não foi autorizado pelo bispo a se casar com a mãe de seus três filhos, com quem já vivia há anos, porque não possuía certidão de nascimento. Embora a historiografia da imprensa não considere que houvesse o gênero da reportagem no século XIX, esse texto se assemelha bastante ao que se desenvolveria como reportagem posteriormente.

É provável que tenha sido na cobertura local que o leitor tenha se visto de forma mais nítida. A coluna “Na polícia e nas ruas”, do Jornal do Brasil, por exemplo, trazia os relatos excitantes dos crimes, nos quais os personagens eram vítimas das tragédias urbanas.

A cobertura local começava a ganhar cada vez mais espaço. A maior dinamização da vida nas cidades, na antiga corte em especial, parece ter levado o cotidiano para dentro das páginas dos periódicos. O mais curioso é que, embora a figura do repórter profissional só se estabelecesse no século seguinte, esses relatos do cotidiano já apareciam intensamente no final do século XIX (MATHEUS, 2011).

Aquilo que chamaríamos hoje de “apuração” havia funcionado ao longo daquele século de forma mais passiva, pois o jornal dependia do recebimento de cartas e de outros periódicos a serem compilados e de uma nova forma de captação de notícias: os telegramas. De certo modo, o modelo se assemelhava ao que ocorre hoje no jornalismo online, que se caracteriza muito mais por um trabalho de edição, de composição, do que de investigação direta. Essa forma indireta de coleta de notícias fazia sentido dentro daquele circuito pelo qual passavam as informações na época, mas, além das guerras e da política, os fatos corriqueiros, que podiam ser comprovados na realidade cotidiana do público comum, iam recebendo mais espaço.

Com quatro páginas, assinatura anual de 24 mil réis, o Diário do Rio de Janeiro era quase que inteiramente voltado para o noticiário cotidiano, a começar pela sua coluna principal de primeira página, chamada "Noticiário”. Em suas páginas, havia uma espécie de cobertura da administração local que ia além da simples reprodução de decretos e atas legislativas, já com explicações mais concretas, como no caso do projeto da construção de um aqueduto em julho de 1870, detalhadamente explicado.

Já a Gazeta de Notícias, primeiro periódico no Brasil a assinar o serviço noticioso da Havas, em 1875, dava bastante espaço à cobertura local. Com viés popular, o periódico 
contava as dificuldades do povo, como no caso da perseguição aos não-vacinados e da aplicação de multas, muito antes da famosa Revolta da Vacina, de 1904.

\begin{abstract}
Multas municipaes - Há cerca de um mez demos publicidade a um facto que chegou ao nosso conhecimento, relativo a imposição de multas municipaes a uns pobres homens moradores de cortiços, por terem deixado de vaccinar seus filhos. Fizemos ver n’essa occasião que não estando em vigor lei nenhuma que torne a vaccina obrigatória, não podia a autoridade impor pena a quem quer que fosse. (...) A multa ficou no escritório [a redação] e o fiscal foi ver. Chegaram mais duas sem assinatura do fiscal. Se existe uma lei, ela precisa ser do conhecimento de todos. Não censuramos a multa, não consideramos vexatória a imposição da vaccina; pedimos apenas que seja publicada a lei em vigor em que baseam os srs. fiscaes e procurador da Câmara para impor multas aos que não têm seus filhos vaccinados. (Gazeta de Notícias, 10/10/1875, p. 1)
\end{abstract}

O cotidiano vai ganhando espessura nas páginas impressas nesse período. Crimes, doenças, escândalos, denúncias e até a programação cultural dão a dimensão do tempo presente e da presença do cotidiano como notícia, em vez exclusivamente das atas das assembleias e dos ataques políticos. Não foi apenas o factual que tomou parte do lugar das atas. Também os jogos criavam uma espécie de “interatividade” lúdica da época, levando o cotidiano e a dimensão do entretenimento para as páginas impressas. O Paiz publicava os Echos de toda parte, uma nota diária com pelo menos duas piadas, reverberando as vozes da rua. Havia ainda os passa-tempos, palavras cruzadas e os enigmas. Os leitores enviavam as respostas para a redação na esperança de vencer os desafios, que podiam ser desde a solução de uma charada até o desvendamento do funcionamento de uma nova invenção. Outros jornais faziam o mesmo e era comum a publicação diária de poemas enviados pelos leitores. Esses poemas eram crônicas cotidianas do ponto de vista dos leitores, que usavam o recurso para comentar as notícias, as modas, o comportamento. O Fluminense publicou esses poemas até as primeiras décadas do século XX. Os temas podiam ser de lamento, saudade, pêsames, amor e muitas vezes pedidos de perdão, mas também eram comentários de notícias dos dias anteriores.

No intuito de aumentar sua popularidade, os jornais estimulavam a visitação aos seus escritórios. A Gazeta de Notícias informava, em 10 de outubro de 1875, que documentos mencionados numa reportagem poderiam ser verificados por quem quisesse, pois ficariam disponíveis na redação, não só dando prova de sua veracidade, mas também indicando que a visita ao jornal era possível. O Paiz mantinha a nota Salão d'O Paiz onde anunciava a 
exposição de obras de arte que podiam ser apreciadas pelo público na sede, na Rua do Ouvidor. Além de publicar diariamente conselhos e charadas, O Paiz usava amplamente o recurso de estimular a visita a sua redação, como neste caso, em que cria desafios lúdicos aos leitores:

\begin{abstract}
Salão d’O Paiz
No nosso salão expomos hoje um engenhoso aparelho destinado por seu inventor, o Sr. Salvador Joaquim Pires, a prestar-se como fechadura da maior segurança em moveis, burras, portas etc, podendo ser aberto ou fechado por dez mil modos completamente diversos e desencontrados (...) Na caixa que hoje expomos, e onde se acha apllicada a curiosa fechadura, há uma nota de vinte mil réis nella collocada pelo inventor á nossa vista, nota essa que, além da quantia de cincoenta mil réis que será mais tarde entregue, pertencerá ao paciente que conseguir abrir o terrível e garantidor aparelho. (O Paiz, 06/07/1890, p. 1)
\end{abstract}

Assim, talvez, muitas das invenções da época tenham sido apresentadas pelos jornais de forma curiosa, incentivando a participação do público, que crescia numericamente e também em interesse a cada dia.

Apenas cinco anos depois de sua fundação, a Gazeta de Notícias eliminaria as seções “Boletim Parlamentar” e “Diário das Câmaras”, substituindo-as pelos “Assuntos do Dia”- (Barbosa, 2007, p. 29). Surgem as seções "Miscellania”, "Noticiário”, "Ronda das Ruas”, "Plantão”, “Hóspedes e Viajantes”, "Polícia”, “Occurrencias” (em O Fluminense); “Na Polícia e nas Ruas”, “Diário da Cidade”, “Hóspedes e Viajantes” (no Jornal do Brasil). Todas essas colunas eram dedicadas não apenas aos crimes, mas a informações úteis em geral, como plantão de delegados, de médicos, chegada e saída de forasteiros, enfim, à dinâmica no espaço urbano. Desde seu lançamento, em 1891, o Jornal do Brasil publica a coluna "Dia-adia”, dedicada às “crônicas dos acontecimentos diários” (JB, 30/12/1891, p. 1). Essas colunas materializavam linguisticamente a temporalidade do cotidiano, esse tempo que inclui todas as dimensões da vida social e que se confunde com o próprio tempo do jornalismo (MATHEUS, 2011).

Aquilo a que se está chamando cotidiano é um conceito complexo que, embora muitas vezes seja erroneamente tratado como "rotina”, inclui rotina, mas que também incorpora a reflexão acerca da realidade e sua efetiva transformação. "O cotidiano é a vida do homem inteiro” (HELLER, 1992, p. 17). Nele, o homem experimenta sua integralidade, tanto 


\section{míDiA

com seus hábitos mais firmemente estabelecidos quanto com as surpresas que suas ações e as dos outros produzem no curso da própria vida e na dos demais.

Mas a cotidianidade não poderia ser descrita mais literalmente do que pela perecibilidade da carne na coluna do $J B$ “O BIFE”, espécie de boletim de matadouros, na qual se anunciavam diariamente as rezes abatidas, onde e por quanto comprar "a carne verde", como era chamada a carne fresca.

Até os jornais não tão dedicados a reportagens locais, como o Jornal do Commercio, passam a dar maior dinâmica a seu conteúdo, destacando a vida diária, por exemplo, na coluna "Várias Notícias”, principalmente as tragédias, como este acidente na Bahia:

Hontem quando da recolhida ao quartel do forte S. Pedro a 54 de voluntários, o povo que acompanhava pretendeu, como de costume, entrar na fortaleza, mas tendo sido prohibida sua entrada, recuou em massa sobre a ponte que forma o passadiço da entrada, e aperdado entre a repulsa do interior do quartel e a onde que também para dentro se encaminhava, fez grande peso sobre a ponte, que cedeu, perdendo um dos parapeitos; cahirão no fosso do lado direito mais de cincoenta pessoas, das quaes muitas ficarão feridas e algumas gravemente (Jornal do Commercio, 14/09/1870, p. 1).

O cotidiano seria a condição de aproximação dos jornais com o grande público. Trata-se do lugar de onde os jornais extraem tanto o extraordinário quanto o banal, a vida dos homens comuns, os dramas e tragédias que seduzem o leitor. Foi esse tipo de conteúdo que levou o princípio da factualidade a funcionar como parâmetro para a atividade jornalística. (SCHUDSON, 2010) Os fatos tomaram o lugar do debate de ideias e dos ataques políticos, ao que Lage chama publicismo (2011). E os fatos não são extraídos de outro lugar que não do cotidiano.

\section{Considerações finais}

Alguns jornais do final do século XIX, como a Gazeta de Notícias e $O$ Fluminense, já eram bastante noticiosos, considerando o que hoje compreendemos como notícia. Não se trata de desconhecer as particularidades de cada época, mas de compreender as mudanças à luz do passado e de reconhecer a contribuição do público para as configurações do jornalismo. Os jornais são consumidos dentro de uma dinâmica cultural, cuja participação do público precisa ser destacada, de modo a considerar o leitor numa perspectiva ativa. 
Com a crescente ampliação da rede telegráfica no território nacional, surgiu também uma nova modalidade de participação do leitor no processo jornalístico. Embora fosse possível enviar cartas ou mesmo ir às redações conversar com os editores, o telégrafo mobilizou o leitor espalhado por todo o território. Encontramos, por exemplo, a divulgação, por telegrama, ao Jornal do Commercio, em 16 de dezembro de 1890, de uma festa numa escola em Campos dos Goytacazes, município a 286 km do Rio, entre outros exemplos do que parecia ser divulgação espontânea. Entretanto, esse tipo de divulgação era bem mais raro.

O público ao qual nos referimos, evidentemente, é um leitor bastante privilegiado no sistema comunicacional da época. Ele podia ser um agente estrategicamente posicionado, como o telegrafista, mas também os dignatários da época - juízes, comissários e outras autoridades. Mas essa posição privilegiada não os exclui da condição de público, mesmo que eles já gozassem de acesso aos periódicos antes da ampliação da rede telegráfica.

O director dos telegraphos visitou a estação central da estrada de ferro D. Pedro II, examinando as condições electricas dos fios, começando assim a uniformização do serviço telegraphico das estradas de ferro (Seção “A pedidos”, Diário de Notícias, 05/07/1885, p. 1).

O exemplo acima parece tratar de um telegrama enviado pelo telegrafista, como uma espécie de divulgação oficial das atividades referentes à Repartição Geral dos Telégrafos (RGT), que administrava a rede pública. Entretanto, a contribuição mais frequente com o envio de telegramas vinha de outras províncias, de redações aliadas, que colaboraram umas com as outras.

\footnotetext{
Ouro Preto, 24

O engenheiro Grey Tavares assignou hoje pela Companhia Industrial de Ouro Preto o controle para o serviço de illuminação electrica d'esta capital. Grande animação da população.

Prepara-se manifestação ao dr. Governador e às Companhias Industrial e Construtora da nova cidade de Ouro Preto - Redacção do Repórter.

(Diário de Notícias, 25/07/1890, p. 1)
}

O Repórter era um semanário de Ouro Preto (MG) e assíduo colaborador dos periódicos do Rio. Nossa hipótese é que fosse prestigioso um jornal ter seu nome divulgado nos grandes títulos. Mas não só por isso. Se o editor de $O$ Repórter quisesse estabelecer diálogo com as autoridades da federação, deveria ter sua voz reverberada, afinal, na capital, 
onde se encontrava o poder. Com isso, jornais de diferentes províncias formavam uma rede de colaboração que incluía, ainda que de forma esparsa, iniciativas espontâneas dos leitores. Tanto o Jornal do Commercio quanto O Paiz e A Cidade do Rio, de José do Patrocínio, recebiam telegramas de outros jornais de todas as províncias litorâneas e de Minas Gerais, além de receberem também de correspondentes individuais nacionais e estrangeiros.

Recife, 30 de Novembro

O povo reunido em praça publica pedia pão e trabalho. Mais de 10,000 pessoas acclamarão oradores os Dr. Antero Furtado, Dr. José Braziliano e Fortunato Pinheiro. O governador garantio satisfazer o pedido auxiliado pelo presidente da intendência. Grande enthusiasmo. (do Jornal do Commercio)

(Jornal do Commercio, 1/12/1890, p. 1)

O telegrama acima, por exemplo, era assinado pelo próprio Jornal do Commercio e devia partir de algum colaborador local, em Recife. É preciso ressaltar que essas colaborações - tivessem ou não caráter comercial (o que não foi possível verificar) - se davam de forma independente da agência Havas, como no exemplo anterior. O mesmo ocorria inclusive com telegramas estrangeiros no caso do Jornal do Commercio.

Portanto, se o contexto atual das comunicações apresenta uma cultura participativa inédita, segundo a qual o público é capaz de interagir e colaborar com a grande mídia e repercutir imediatamente seus produtos jornalísticos, também é verdade que encontramos experiências colaborativas num passado remoto, com o envio de telegramas noticiosos às redações, às trocas de notícias entre os diferentes jornais, quando não eram concorrentes diretos, assim como a interação do leitor nos jogos, promoções e charadas.

\section{Referências}

BARBOSA, Marialva. Carlos. História cultural da imprensa. Brasil - 1800-1900. RJ: Mauad $\mathrm{X}, 2010$.

BOURDIEU, Pierre. A economia das trocas linguísticas. São Paulo: Edusp, 2008,

BRAMBILLA, Ana Maria. A reconfiguração do jornalismo através do modelo open source. Sessões do imaginário, 2005. Disponível em: www6.ufrgs.br/limc/PDFs/reconfig.pdf

BRAMBILLA, Ana Maria. Jornalismo open source em busca de credibilidade: como funciona o projeto sulcoreano OhMyNews International, São Paulo: Intercom, 2005. 
FONSECA, Virginia e LINDEMANN, Cristiane. Webjornalismo participativo: repensando algumas questões técnicas e teóricas Revista FAMECOS • Porto Alegre $\bullet n^{\circ} 34 \cdot$ dezembro de 2007.

HELLER, Agnes. O cotidiano e a história. São Paulo: Paz e Terra, 1992.

LAGE, Nilson. A reportagem: teoria e técnica de entrevista e pesquisa jornalística. RJ: Record, 2011.

LEMOS, André. Anjos Interativos e Retribalização do Mundo: Sobre Interatividade e Interfaces Digitais. Signo Revista de Comunicação, João Pessoa, ano III, nº 5, p. 26-42, 1998.

MATHEUS, Leticia Cantarela. Comunicação, tempo, história: tecendo o cotidiano em fios jornalísticos. RJ: Mauad-X, 2011.

MATHEUS, Leticia Cantarela. O Jornalismo e o Sistema Telegráfico no Brasil no Final do Século XIX. Intercom, Fortaleza, 2012.

PRIMO, Alex. Enfoques e desfoques no estudo da interação mediada por computador. 404NotFound, n. 45, 2005.

PRIMO, Alex; TRÄSEL, Marcelo Ruschel. Webjornalismo participativo e a produção aberta de notícias. Contracampo (UFF), v. 14, p. 37-56, 2006.

QUADROS, Claudia Irene. A participação do público no webjornalismo. Anais do III Encontro de Pesquisadores em Jornalismo, Florianópolis, nov. de 2005.

ROCHA, Jorge; BRAMBILLA, Ana Maria. Comunicação relacional e as mediações possíveis no Jornalismo Colaborativo. Anais do VII Encontro Nacional de Pesquisadores em Jornalismo - SBPJor, São Paulo, 2009.

SCHUDSON, Michael. Descobrindo a notícia. Uma história social do jornais nos Estados Unidos. Petrópolis (RJ): Editora Vozes, 2010.

SODRÉ, Muniz. O monopólio da fala. Rio de Janeiro: Vozes, 1977.

\section{Material empírico analisado e documentos pesquisados}

BERTHOLD, Victor.M. History of the Telephone and the Telegraph in Brazil - 1851-1921. New York: University of Michigan Library, 1922.

BRASIL. Repartição Geral dos Telégrafos. Memória Histórica. Rio de Janeiro: Imprensa Nacional, 1909.

BRASIL. Repartição Geral dos Telégrafos. Relatório dos anos 1889/1890. Rio de Janeiro: Imprensa Nacional, 1891.

OLHAR UNIVERSITÁRIO. Ainda há espaço para intelectuais na televisão? Programa gravado dia 03/11/2011, no Centro Universitário Plinio Leite, Niterói, RJ.

A Cidade do Rio, outubro e dezembro de 1890. 
A Pátria (Niterói-RJ), outubro de 1871.

Correio da Noite (MG), janeiro de 1890.

Diário de Notícias, julho de 1885, julho de 1890.

Diário do Rio de Janeiro, julho de 1870, abril de 1878.

Gazeta da Tarde, agosto de 1890.

Gazeta de Notícias, outubro de 1875, fevereiro de 1879, agosto de 1890.

Jornal do Brasil, dezembro de 1891, abril de 1897.

Jornal do Commercio, setembro de 1870, julho de 1872, abril de 1877, fevereiro de 1879, julho de 1881, junho de 1883, maio de 1887, dezembro de 1890, setembro de 1892, junho de 1897, dezembro de 1899, janeiro de 1900.

O Fluminense (Niterói-RJ), maio e julho de 1888, julho de 1892, abril de 1897, julho e setembro de 1898.

O Paiz, dezembro de 1890, julho de 1892.

O Repórter (MG), agosto de 1890. 